\title{
Correction of "Case Study: A Simulation Model of the Spawning Stock Biomass of Pacific Bluefin Tuna and Evaluation of Fisheries"
}

\author{
Kazumi Sakuramoto \\ Department of Ocean Science and Technology, Tokyo University of Marine Science and Technology, Tokyo, Japan \\ Email:sakurak@kaiyodai.ac.jp
}

How to cite this paper: Sakuramoto, K. (2017) Correction of "Case Study: A Simulation Model of the Spawning Stock Biomass of Pacific Bluefin Tuna and Evaluation of Fisheries". Open Access Library Journal, 4: e3575.

https://doi.org/10.4236/oalib.1103575

Received: March 31, 2017

Accepted: April 24, 2017

Published: April 28, 2017

Copyright (๑) 2017 by author and Open Access Library Inc.

This work is licensed under the Creative Commons Attribution International License (CC BY 4.0).

http://creativecommons.org/licenses/by/4.0/

\begin{abstract}
One error was found in the coding of the simulation program for reproducing the recruitment $(R)$ and spawning stock biomass $(S S B)$ of Pacific bluefin tuna. As a result of this error, the maturity rates for ages 3 and 4 were found to be much lower in the simulation than the true values. The aim of this paper is to show the results when the error is corrected. The $R$ and $S S B$ were underestimated in response to the error. As a result, the natural mortality coefficients $(M)$ in the previous paper were assumed to be smaller so that the reproduced $R$ and $S S B$ would coincide with those observed. When the error was corrected, it was not necessary to assume the value of $M$ to be smaller. When the corrected progam and the original $M$ values were used, the $R$ and $S S B$ reproduced in the simulation coincided well with those shown in the previous paper.
\end{abstract}

\section{Subject Areas \\ Marine Biology}

\section{Keywords}

Bluefin Tuna, Stock-Recruitment Relationship, Environmental Factors

\section{Introduction}

The abundance of Pacific bluefin tuna, Thunnus thynnus, has seriously decreased in recent years. In 1952, the starting year of the current stock assessment, total stock biomass was 119,400 t. During the stock assessment period, the total stock biomass reached the historical maximum of $185,559 \mathrm{t}$ in 1959 , and a historical minimum of 40,263 $\mathrm{t}$ in 1983 . Total stock biomass started to increase again in the mid-1980s and reached its second highest peak of 123,286 t in 1995. 
Total stock biomass decreased throughout 2008-2012, averaging 50,243 t per year, but reached $44,848 \mathrm{t}$ in 2012 [1]. Recovering the stock abundance has become an urgent issue. In order to discuss optimal management procedures, it is important to understand the stock-recruitment relationship $(S R R)$ for this species; however, a clear relationship between recruitment $(R)$ and spawning stock biomass ( $S S B$ ) has not been detected, and the recruitment seems to fluctuate regardless of the level of $S S B$. Whether or not a clear relationship between $R$ and $S S B$ can be detected is important, because if $R$ does not show a clear relationship to $S S B$, we cannot expect a fisheries regulation directly aimed at increasing $R$ to have any effect on the end goal, which is to increase $S S B$. In this case, the more effective regulation would be to manage the population after they are recruited. Recently, however, Sakuramoto proposed a new stock-recruitment relationship for Pacific bluefin tuna [2] [3] [4] [5] that incorporated environmental factors instead of assuming a density-dependent effect. The estimated model shown in the previous paper was expressed as follows [2]:

$$
\begin{aligned}
\ln \left(R P S_{t}\right)= & 3.6511-0.1588 A_{2, t}+0.1357 A_{3, t}+0.1784 A_{4, t}+0.4435 A_{6, t}+0.2635 A_{7, t} \\
& -0.1960 P_{4, t}+0.3154 P_{9, t}-0.4624 P_{10, t}+0.2254 R_{\text {sardin }, t},
\end{aligned}
$$

where $A_{m, t}$ and $P_{m, t}$ denote the Arctic Oscillation (AO) in month $m$ of year $t$ and the Pacific Decadal Oscillation (PDO) in month $m$ of year $t$, respectively. $R_{\text {sardine,t }}$ denotes the recruitment of the Pacific stock of Japanese sardines in year $t$. The natural logarithm of the recruitment per spawning stock biomass (RPS) is denoted by $\ln (R P S)$. Using Equation (1), $R$ and $S S B$ were reproduced provided that the numbers of fish by age in year 1952 were given as the initial values and that environmental factors such as $\mathrm{AO}, \mathrm{PDO}$ and the recruitment of sardines were known. The procedure by which $R$ and $S S B$ were reproduced was explained in detail in the previous paper [2]. However, it was recently found that one line in the program that calculated the matured stock was miscoded.The aim of this paper is to show the results when the error is corrected and the original $M$ values are used.

\section{Methods}

\subsection{Data}

For Pacific bluefin tuna, data on the recruitment and spawning stock biomass from 1952 to 2012 were used [1]. Data on the recruitment of the Pacific stock of Japanese sardines were used [6] [7]. The indexes of the AO by month and the PDO by month from 1952 to 2012 were obtained from the NOAA Climate Prediction Center [8] and the NOAA's National Centers for Environmental Information [9], respectively.

\subsection{Simulation Program Coded by MATLAB Software}

The simulation program was coded with MATLAB software Version R2013b. The incorrect sentence in the program is as follows:

$$
\operatorname{Stcal}(t+1)=\operatorname{Stcal}(t+1)+\operatorname{mature}(t+1, a) * \operatorname{SSBcal}(t+1, a),
$$


where $\operatorname{Stcal}(t+1)$, mature $(t+1, a)$, and $\operatorname{SSBcal}(t+1, a)$ denote the calculated values of $S S B$ in year $t+1$, the maturity rate at age $a$ in year $t+1$, and the calculated values of $S S B$ at age $a$ in year $t+1(a=0,1, \ldots, 10+)$, respectively. The line should be replaced by the following:

$$
\operatorname{Stcal}(t+1)=\operatorname{Stcal}(t+1)+\operatorname{SSBcal}(t+1, a) .
$$

That is, the maturity rate, mature $(t+1, a)$, in Equation (2) should be removed. As a result of this error, the maturity rates for ages 3 and 4 were doubly multiplied. The maturity rates for ages 0 to 2 are zero, and those for ages 5 and older are unity; therefore, the values calculated with Equations (2) and (3) are not different for ages 0 to 2 and for ages 5 and older. However, the true maturity rates for ages 3 and 4 are 0.2 and 0.5, respectively. When Equation (2) is used, the rates of matured fish at ages 3 and 4 are wrongly calculated by multiplying $0.2 * 0.2=0.04$ and $0.5 * 0.5=0.25$ by the number of fish of those ages, respectively. That is, the numbers of matured fish at ages 3 and 4 were much smaller than the true values. This caused the underestimation of $R$ and $S S B$.

\subsection{When Original Natural Mortality Coefficients Were Used}

In the previous paper, the smaller natural mortality coefficients were used so as to minimize the differences between the observed and calculated values of $R$. However, an additional modification of $M$ was necessary in response to the error. This paper shows the results when the program is corrected and the original $M$ values, 0.375 for age $0,0.45$ for age 1, and 0.04 for age 2 and older, are used.

\section{Results}

\section{Reproductions of $R, S S B$ and Catch When the Error Is Corrected with Lower $M$ Values}

Figure 1 shows the reproduced $R_{t}, S_{t-1}$ and catch in year $t$ that were shown in the previous paper and those that were newly calculated in the present paper using Equation (3) with lower $M$ values. When Equation (3) was used with lower M values, the reproduced values of $R_{t} S_{t-1}$ and the catch were larger than the observed values and the reproduced values determined using Equation (2) with lower $M$ values.

Figure 2 shows the case when Equation (3) and the original $M$ values are used. In this case, the reproduced $R_{t}, S_{t-1}$ and catch values coincided well with those shown in the previous paper. That is, the new reproduced values coincided well with those calculated using Equation (2) with a lower natural mortality coefficient $M$.

\section{Discussion}

This paper showed that the results obtained when the wrong program and lower $M$ values were used coincided well with the results obtained when the corrected program and the original $M$ values were used. This indicates that the maturity rates and natural mortality coefficients are deeply related to each other. 

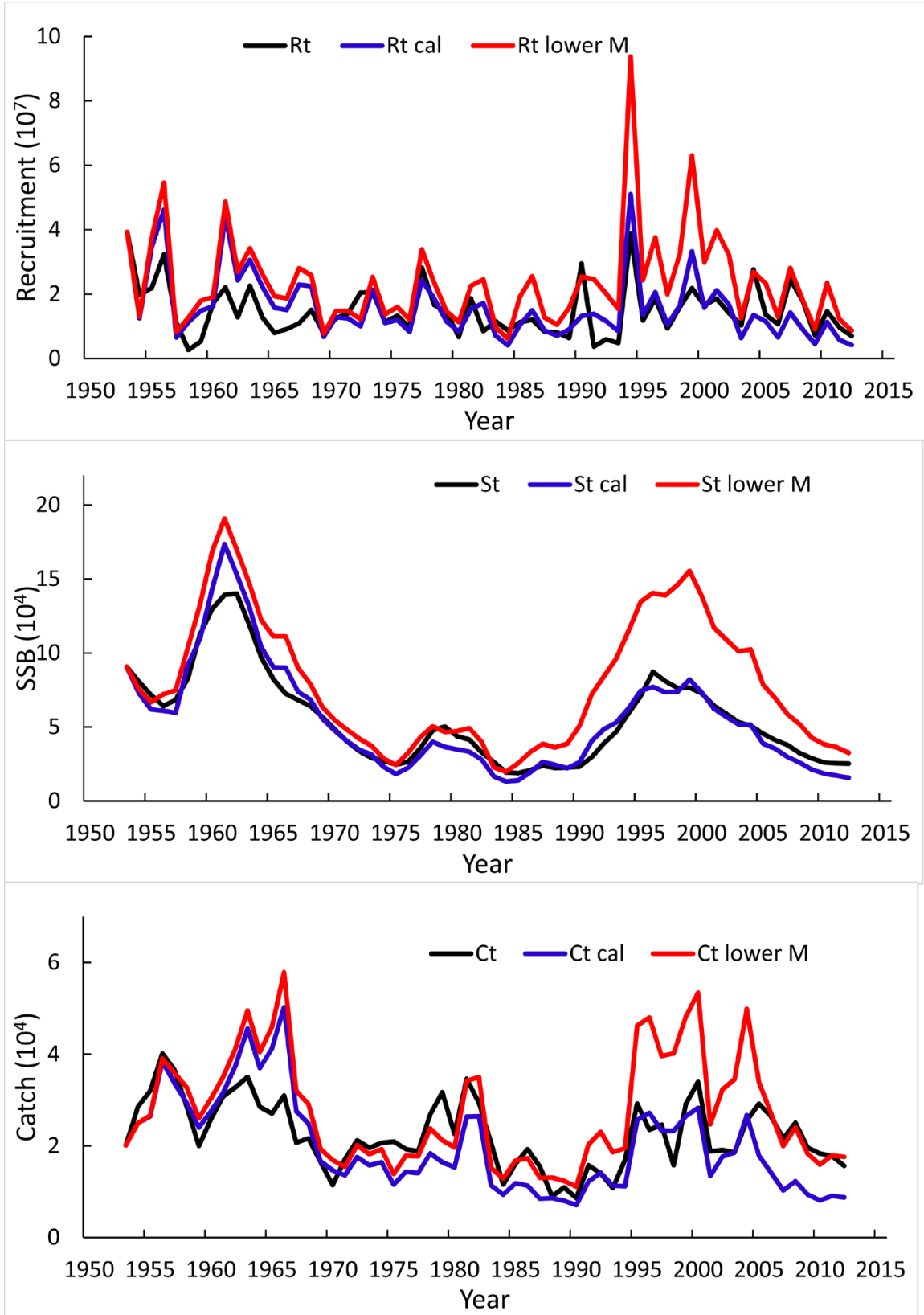

Figure 1. Observed and reproduced recruitment, $S S B$, and catch. Black, blue, and red show the values inferred, reproduced by the incorrect program with the lower $M$, and reproduced by the corrected program with the lower $M$ was used, respectively.

In addition, there are also deep relationships among other parameters including the fishing mortality coefficients, the natural mortality coefficients, and weight by age. Therefore, the fit between the observed $R$ and $S S B$ and the reproduced $R$ and $S S B$ would be much better when these parameters were estimated using an optimization technique.

When the same fisheries regulations used in the previous paper [2] were used here, their effects were almost the same as in the previous paper. That is, the regulation prohibiting fishing for 0 - and 1-year-old fish was effective in terms of recovering the spawning stock biomass. The reduction of the fishing mortality 

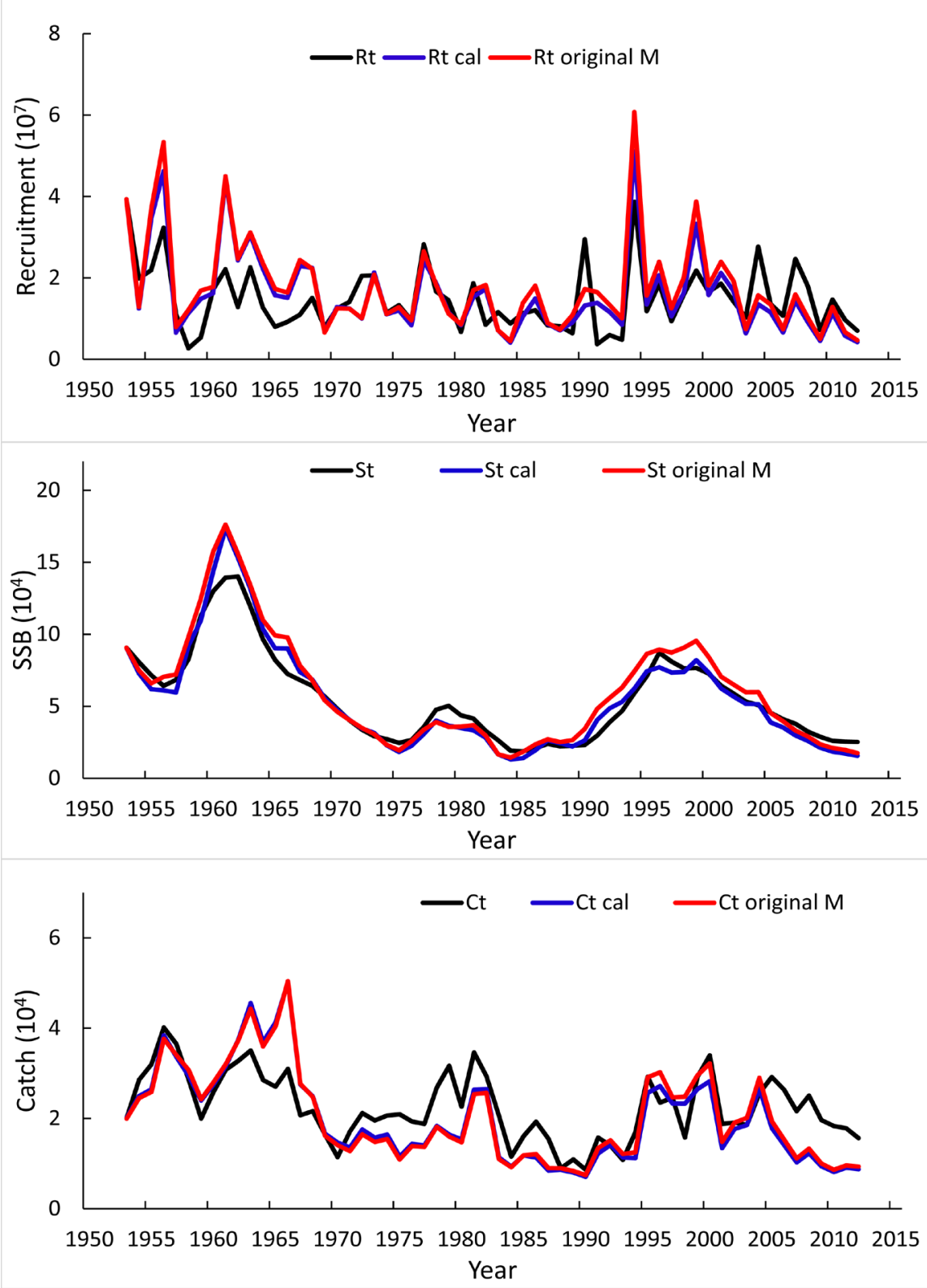

Figure 2. Observed and reproduced recruitment, $S S B$, and catch. Black, blue, and red show the values inferred, reproduced by the incorrect program with the lower $M$, and reproduced by the corrected program with the original $M$, respectively.

coefficients for fish at all ages to $50 \%$ of the actual values also showed a good performance.

The estimated $R$ and $S S B$ were revised by the International Scientific Committee in 2016. However, in this study the old estimated values were used, because the aim of this study was to show the differences in results between the in corrected and corrected programs. However, the essential problem is not different when the revised estimates of $R$ and $S S B$ are used.

\section{Conclusions}

The results obtained when the wrong program and lower $M$ values were used 
coincided well with those obtained when the corrected program and original $M$ values were used. The conclusions obtained in the previous paper [2], which are shown below, were still valid.

1) Recruitment per spawning stock biomass of Pacific bluefin tuna can be reproduced by using the Arctic Oscillation by month, Pacific decadal oscillation by month and the recruitment number of the Pacific stock of Japanese sardine.

2) Spawning stock biomass could be well reproduced by using the simulation model that was constructed with the recruitment per spawning stock biomass and the survival process of population that included the effect of fishing.

3) The effective regulation in the simulations conducted in this paper was a prohibition of fishing for 0 - and 1-year-old fish in terms of recovering the spawning stock biomass. The reduction of fishing mortality coefficients for fish of all age to $50 \%$ of actual values also showed a good performance.

4) The recent reductions of the recruitment and spawning stock biomass appear to be caused by the unregulated harvests, especially for immature fish, since 2004.

\section{Acknowledgements}

I would like to thank Dr. N. Suzuki for his useful comments that improved this manuscript.

\section{References}

[1] Pacific Bluefin Tuna Working Group (PBFWG) (2014) Stock Assessment of Bluefin Tuna in the Pacific Ocean in 2014. Report of the Pacific Bluefin Tuna Working Group, International Scientific Committee for Tuna and Tuna-like Species in the North Pacific Ocean, 1-121.

http://isc.fra.go.jp/pdf/2014_Intercessional/Annex4_Pacific\%20Bluefin\%20Assmt\% 20Rport\%202014-\%20June1-Final-Posting.pdf

[2] Sakuramoto, K. (2013) A Recruitment Forecasting Model for the Pacific Stock of the Japanese Sardine (Sardinops melanostictus) that Does Not Assume Density-Dependent Effects. Agricultural Sciences, 4, 1-8.

[3] Sakuramoto, K. (2014) A Common Concept of Population Dynamics Applicable to both Thripsimaginis (Thysanoptera) and the Pacific Stock of the Japanese Sardine (Sardinops melanostictus). Fisheries and Aquaculture Journal, 4, 140-151.

[4] Sakuramoto, K. (2015) Illusion of a Density-Dependent Effect in Biology. Agricultural Sciences, 6, 479-488. https://doi.org/10.4236/as.2015.65047

[5] Sakuramoto, K. (2016) Case Study: A Simulation Model of the Spawning Stock Biomass of Pacific. Bluefin Tuna and Evaluation of Fisheries Regulations. American Journal of Climate Change, 5, 245-260. https://doi.org/10.4236/ajcc.2016.52021

[6] Kawabata, J., Honda, S., Watanabe, C., Okamura, H. and Ichinokawa, M. (2014) Stock Assessment and Evaluation for the Pacific Stock of Japanese Sardine (Fiscal Year 2013). In: Marine Stock Fisheries Stock Assessment and Evaluation for Japanese Waters (Fiscal Year 2013/2014), Fisheries Agency and Fisheries Research Agency, Japan, 15-46,

[7] Yatsu, A., Watanabe, T., Ishida, M., Sugisaki, H. and Jacobson, L.D. (2005) Environmental Effects on Recruitment and Productivity of Japanese Sardine Sardinops melanostictus and Chub Mackerel Scomber japonicus with Recommendations for 
Management. Fisheries Oceanography, 14, 263-278.

https://doi.org/10.1111/j.1365-2419.2005.00335.x

[8] AO (Arctic Oscillation, NOAA Climate Prediction Center) (2015).

http://www.cpc.ncep.noaa.gov/products/precip/CWlink/daily_ao_index/monthly.a o.index.b50.current.ascii

[9] NOAA's National Centers for Environmental Information (NCEI) (2015) Pacific Decadal Oscillation (PDO). https://www.ncdc.noaa.gov/teleconnections/pdo/

Submit or recommend next manuscript to OALib Journal and we will provide best service for you:

- Publication frequency: Monthly

- 9 subject areas of science, technology and medicine

- Fair and rigorous peer-review system

- Fast publication process

- Article promotion in various social networking sites (LinkedIn, Facebook, Twitter, etc.)

- Maximum dissemination of your research work

Submit Your Paper Online: Click Here to Submit

Or Contact service@oalib.com 